\title{
Effect of Integrated Pictorial Handbook Education and Counseling on Improving Anemia Status, Knowledge, Food Intake, and Iron Tablet Compliance Among Anemic Pregnant Women in Indonesia: A Quasi-Experimental Study
}

This article was published in the following Dove Press journal: Journal of Multidisciplinary Healthcare

\author{
Putri Nahrisah (1D) ${ }^{1,2}$ \\ Ratana Somrongthong' \\ Napaphan Viriyautsahakul (D) \\ Pramon Viwattanakulvanid (iD) \\ Samlee Plianbangchang' \\ 'College of Public Health Sciences, \\ Chulalongkorn University, Pathumwan, \\ Bangkok 10330, Thailand; ${ }^{2}$ Health Office \\ of Kota Langsa Municipality, Kota Langsa, \\ Province of Aceh, Indonesia
}

Purpose: To determine the effect of individual education through a pictorial handbook on anemia in conjunction with counseling on improving hemoglobin and hematocrit level, birth weight, knowledge, iron-rich food and iron-folic acid (IFA) intake.

Patients and Methods: The study developed a pictorial handbook that was conceptualized based on the Health Belief Model and adjusted to some cultural and local contexts. A quasiexperimental pre-test-post-test control group design was used, purposefully conducted between two homogenous municipalities, each having a rate of anemic pregnancy that was $40 \%$ or greater. The sample consists of 140 anemic pregnant women randomly allocated via lottery into two groups; the intervention group $(n=70)$, which received two home visits - one for education and another for a counseling session, and control group $(n=70)$, which received routine antenatal care. A chi-square test and a Mann-Whitney $U$-test were conducted to compare the baseline socio-demographics. An analysis of covariance (ANCOVA), controlling some possible confounders, was performed to analyze the effect of intervention.

Results: The post-test means of hemoglobin $\mathrm{F}(1,132)=122$, p-value $<0.001$, and hematocrit levels $\mathrm{F}(1,132)=373$, p-value $<0.001$, were significantly different and higher in the intervention group compared to the control group. Similar results were found in knowledge, food frequency score, number of IFA intake (with p-value $<0.001$ ), birth weight and daily iron intake from food (with p-value $<0.05$ ). The intervention had a particularly large effect on food frequency score and number of IFA intake, and medium effect on hemoglobin and hematocrit levels.

Conclusion: Individual education through a pictorial handbook on anemia in conjunction with the counseling intervention program had a positive impact on hemoglobin and hematocrit levels for anemic pregnant women in their third trimester of pregnancy.

Keywords: anemia pictorial handbook, health believe model, hemoglobin
Correspondence: Samlee Plianbangchang College of Public Health Sciences, Chulalongkorn University, Institute Building 2-3, Soi Chulalongkorn 62, Phyathai Road, Pathumwan, Bangkok 10330, Thailand

Tel +6622188193

Fax +6622556046

Email samleep40@gmail.com

\section{Introduction}

Iron deficiency anemia (IDA) is the most common anemia globally, and typically results when the intake of dietary iron is inadequate for hemoglobin synthesis. ${ }^{1-3}$ Anemic pregnancy refers to a hemoglobin level below $11 \mathrm{~g} / \mathrm{dL}$, or a hematocrit level below 33\%. ${ }^{1}$ The global prevalence of anemic pregnancy has decreased only slightly, from $41.6 \%$ in 2000 , to $40.1 \%$ in 2016 ; prevalence ranged between $19.6-63 \%$ in 
developing countries and $17.4-34.4 \%$ in developed countries. ${ }^{4}$ A national health survey of Indonesia reported a $37.1 \%$ rate of anemic pregnancy during $2013,{ }^{5}$ which has since increased to $42 \%{ }^{4}$ Furthermore, postpartum hemorrhage (30.3\%), hypertension $(27.1 \%)$, and infection $(7.3 \%)$, which were aggravated by the condition of anemia, were the leading causes of the maternal mortality rate of 359 deaths per 100,000 live births. ${ }^{6}$

In Indonesia, anemia programs for pregnancy are mostly delivered through antenatal care (ANC); hemoglobin measurement, education on dietary intake, and distribution of iron-folic acid (IFA) tablet at a minimum of 90 tablets - one tablet per day. ${ }^{6}$ In fact, studies have revealed that $49 \%$ of pregnant women in Indonesia suffer from insufficiency of energy and up to $85 \%$ from insufficiency of iron. ${ }^{7}$ Yet, only $33.3 \%$ of pregnant women take IFA tablets at the recommended rate of one tablet per day for 90 days. ${ }^{5}$

Tailoring culturally resonant nutrition education and counseling about diet during pregnancy, lactation, weight gain during pregnancy, and monitoring of the progress of maternal nutrition are all areas of needed attention. ${ }^{8}$ Thus, we took the initiative to develop an anemia teaching material that adjusts with cultural and local context. The information is suitable for the needs of pregnant women, is presented using words that are easy to understand, and allows behavior changes in accordance with the characteristics of the community and its environment.

The use of printed education materials promoted an improvement in healthy eating in low-middle income countries (LMICs). ${ }^{9}$ The materials provide permanent and reliable information after verbal communication and education. ${ }^{10}$ Beyond this, there are basic difficulties involved in using information and communication technology in LMICs, such as inadequate physical infrastructure, insufficient access to the hardware for the majority of the population, and lack of the requisite skills for using them. ${ }^{11}$ Likewise, in the province of Aceh, although the percentage of households which owned and were versed in the use of cellular phones was $86.78 \%$, a prevalence of sharing communication devices was indicated, as the percentage of individual ownership of cellular phones was $65.29 \% .^{12}$ The percentage of households which owned and were versed in the use of computers was $18.5 \%$, and only $46.76 \%$ of females accessed the Internet. ${ }^{12}$ Thus, we decided to develop the teaching material in the form of a pictorial handbook.

The anemia pictorial handbook was conceptualized based on the Health Believe Model (HBM) theory. Key elements of the HBM focus on individual beliefs about health conditions, which predict individual health-related behaviors. ${ }^{13}$ The model defines the key factors that influence health behaviors as an individual's perceived threat to sickness or disease (perceived susceptibility), belief of consequence (perceived severity), potential positive benefits of action (perceived benefits), perceived barriers to action, exposure to factors that prompt action (cues to action), and confidence in ability to succeed (self-efficacy). ${ }^{13,14}$ Studies in Iran, ${ }^{15,16}$ Ethiopia, ${ }^{17}$ and Egypt, ${ }^{18}$ showed the effectiveness of HBM combined with a nutrition education program. Yet, none of the studies mentioned prioritize cultural sensitivity in intervention.

Our intervention program was designed to provide an individual education session using the anemia pictorial handbook in conjunction with individual counseling sessions to overcome the barriers to an iron-rich diet and proper IFA intake behavior among $45.9 \%$ of anemic pregnant women in the province of Aceh, Indonesia. ${ }^{19} \mathrm{We}$ invited first time of ANC visitor to participate in the study, to evaluate the effects of the intervention program on hemoglobin and hematocrit levels in their thirdtrimester pregnancies (primary outcome), birth weight, knowledge of anemia, iron-rich food intake, and rate of IFA intake (secondary outcome).

\section{Materials and Methods Study Design}

Our study was a quasi-experimental, pretest- posttest design, purposefully conducted in two municipalities in the province of Aceh, Indonesia, each with an anemic pregnancy prevalence of more than $40 \%$, and which were $170 \mathrm{~km}$ apart. ${ }^{19}$ A simple random sampling, chosen by lottery, assigned Kota Langsa municipality as the intervention area and Kota Lhokseumawe municipality as the control area. Both municipalities were homogenous, respectively, in the following statistics; anemic pregnancy (46.23\% and 43.76\%), pregnant women visiting ANC at least four times (95\% and 90\%), pregnant women receiving at least 90 IFA tablets (95\% and 90\%), low-income families (12.62\% and 12.47\%), population literacy ( $99.9 \%$ and $99.84 \%$ ), and number of villages (66 villages and 68 villages). ${ }^{19,20}$

\section{Sample Size}

It was calculated based on an effect size of nutrition education and counseling towards pregnant women hemoglobin outcome of $0.50 .^{21}$ Using the G-power program 
with an alpha level of 0.05 and a power of 0.80 , plus an additional $10 \%$ of participants to account for attrition, this study required a total of 140 anemic pregnant women, with 70 women in each group.

\section{Participant Recruitment}

All villages in the two municipalities were included in the recruitment process, and we found that a total of 708 first time ANC visitors were registered during March 2018. We invited to participate in the study any pregnant women who met the following criteria; hemoglobin levels below $11 \mathrm{~g} / \mathrm{dL}$, measured by Sahli's haemoglobinometer method, ${ }^{22}$ aged 20 years or above, as the majority of women in Aceh married between the ages of 19-24 years $(53.2 \%),{ }^{20}$ free from obstetrical complication (bleeding, gestational diabetes, pregnancy-induced hypertension), and willing to receive home visits. There were 163 anemic pregnancies; 83 cases in the intervention area and 80 cases in the control area. Three cases in the intervention area and two cases in the control area were excluded due to severe anemia conditions, and these women received a blood transfusion and intense monitoring by the midwife. The 70 participants in each group were gathered through a simple random sampling by lottery (Figure 1).

\section{Ethical Consideration}

This study was approved by the Medical and Health Research Ethics Committee (MHREC) Faculty of Medicine, Universitas Gajah Mada Indonesia (KE/FK/0609/EC/2017). We explained the objectives and data collection processes to participants before asking them to sign a written consent form in the Indonesian language.

\section{Intervention}

Intervention for anemic pregnant women consisted of 2 home visits (45-60 mins) from a well-trained village government midwife. The period between the first home visit and the second home visit was two weeks.

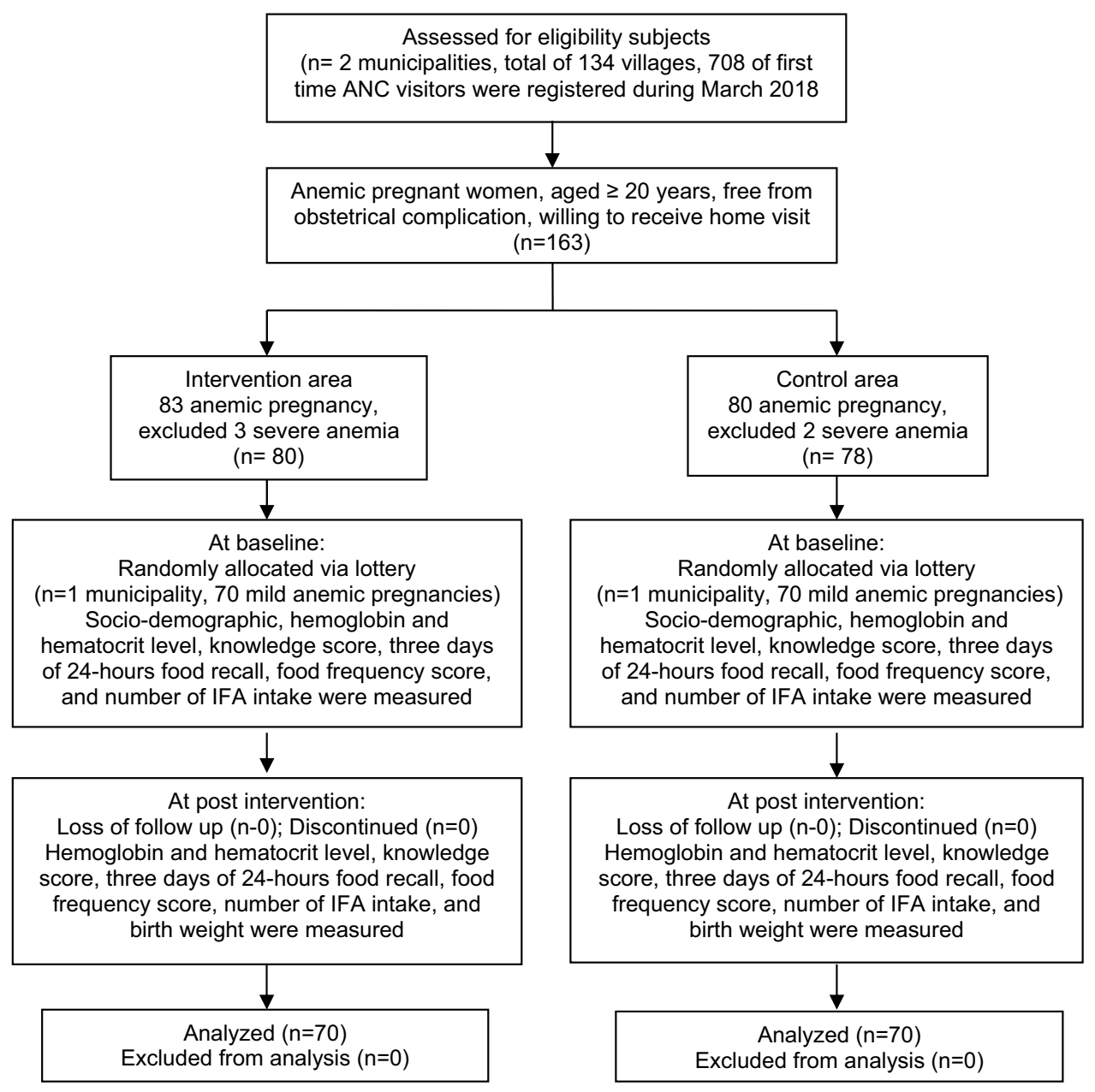

Figure I Flow chart of the study. 
- First home visit - individual education through pictorial handbook. The information on IDA in the pictorial handbook consisted of definitions, signs and symptoms, causes and risk factors, and prevention and treatment, as well as foods rich in iron and recommendations on the intake of IFA tablets. There were pictures available to support the explanation, in addition to pictures of food rich in iron that are affordable, locally available, and recognized by the community.

- Second home visit - individual counseling. This visit emphasized the behaviors of iron-rich food and IFA tablet intake, the benefits of and barriers to iron-rich food and IFA tablet intake, how to cope with the barriers, and susceptibility to and severity of anemic pregnancy.

The information and activities above were designed to fulfill the assumption of the HBM; that is, a person's beliefs about health are determinants of the possibility of the individual to make changes in their lifestyle and behaviors. ${ }^{14}$ During the sessions, the midwife and women discussed how to improve the amount, variety, and frequency of iron-rich food intake with consideration of price, preferences, and accessibility. Creating an atmosphere that supported IFA compliance, such as placing the tablet in an easily seen place, customizing the time of intake, asking the husband or a family member for a reminder and solving the IFA side-effect problem.

The handbook layout creation, formatting, and illustration were carried out by a professional graphic artist. The suitability of handbook - that is, message content, literacy, pictures, and layout — was evaluated through informal interviews with health professionals, including a doctor, a master of community nutrition, a master of health education, and five village government midwives, selected for convenience. After pre-testing for a total of $30 \mathrm{ANC}$ visitors in a districtlevel primary health care unit in the intervention area, the final version was printed with a colorful background and letters, at a length of 21 pages and a size of $17 \mathrm{~cm} \times 12 \mathrm{~cm}$. Due to the Islamic characteristics of society in Aceh, human figures in the book were depicted as Muslim and attached several quotes from the Quran in the handbook. Some iconic places in the intervention area were also illustrated as backgrounds as well.

On the other hand, anemic pregnant women in the control area received routine antenatal care without any further support such as that received by women in the intervention area.

\section{Instruments}

A set of questionnaires measuring socio-demographic information, knowledge of anemia, the $24 \mathrm{hrs}$ food recall questionnaire, along with a food frequency questionnaire (FFQ), were used to measure the outcomes of the study during the pre- and post-intervention periods. The Index of ItemObjective Congruence (IOC) was used by three experts (two doctors and one nutritionist) to check the validity of the questionnaires' content. IOC scores ranged from -1 to +1 . A score of +1 indicated that the item was congruent, while a score of -1 indicated that an item was incongruent, and a score of zero indicated that an item was questionable. The items with average scores lower than 0.5 were revised, and items with average scores greater than or equal to 0.5 were reserved. ${ }^{23}$ A preliminary study to test the questionnaires' consistency reliability was performed, and a Cronbach's alpha coefficient of $>0.70$ was held to indicate reliability. ${ }^{23}$

The knowledge questionnaire consisted of definitions, causes, signs and symptoms, effects of anemia on mother and child health, and methods of preventing anemia. It was developed according to literature review. ${ }^{24}$ A correct answer was scored as "one" and an unknown or incorrect answer was scored as "zero." The total possible score ranged from 0 to 20 points, with higher scores reflecting higher levels of knowledge. The Cronbach's alpha for the knowledge questionnaire was 0.752 .

The $24 \mathrm{hrs}$ food recall questionnaire was used to assess the daily iron intake from food (in $\mathrm{mg} /$ day); nonconsecutive of 2 weeks days and 1 weekend day. ${ }^{25}$ The intake was calculated via the NutriSurvey Indonesia software. The pre-test study resulted in a coefficient correlation of iron intake between two week days was 0.58 , between average of two weeks day and one weekend day was 0.66 . The data included in the analysis were the average intakes across the three days.

The FFQ was used to find the frequency of iron-rich food intake over the past month. We ranked the frequency of intake on a five-level scale: 5 indicated a frequency of more than once a day, 4 of at least once a day, 3 of $4-6$ times per week, 2 of 2-3 times per week, and 1 of once a week or never. ${ }^{26}$ Firstly, the FFQ consisted of 55 foods with iron content no lower than $0.1 \mathrm{mg}$ per $100 \mathrm{~g},{ }^{27}$ selected from the Indonesian food composition tables. ${ }^{28}$ During the pre-test study, only 22 foods were reliable enough to be included in the final version of the questionnaire, with a Cronbach's alpha coefficient of 0.786 . The total possible score ranged from 22 to 110 points; higher scores reflected higher 
frequencies of intake. Evaluation of the rate of IFA intake was done by counting the remaining tablets. The babies' birth weight data were obtained from maternal records.

\section{Data Collection}

Data collectors were nutritionists and laboratory officers working at district-level primary health care units in each area. The questionnaire interview was carried out over about 30-45 mins. The blood sample was analyzed by a Diacon Abacus 3 hematology analyzer. Data were gathered from April to September 2018. Pre- and post-intervention data collection took place over a period of 15 weeks, followed up an average of 10 weeks later for birth weight outcome.

\section{Data Collection}

\section{Data Analysis}

A chi-squared test and a Mann-Whitney $U$-test were conducted to compare the baselines of socio-demographics (age, education, occupation, type of family, monthly family income and gravidity) and pregnancy characteristics (gestation age in weeks) between the intervention and control groups. The Analysis of Covariance (ANCOVA) was performed in this quasi-experimental study to see the effects of intervention. This analysis compares the post-test mean of hemoglobin and hematocrit levels, birth weight, knowledge, daily iron intake from food (mg/day), FFQ score, and number of IFA intake of the two groups (intervention vs control) by controlling or adjusting for the pre-test scores of those variables, as well as possible confounding factors such as age, education, and monthly family income. The data were analyzed using SPSS Statistical Package Version 16 (SPSS Inc, Chicago, IL, USA), with a 95\% CI and p-value $<0.05$.

\section{Results}

\section{Socio-Demographic and Pregnancy Characteristic Variables}

There was no significant difference between the intervention and control groups regarding age, educational level, occupation, type of family, monthly family income, gravidity, or gestational weeks ( $p$-value $>0.05$ ). Among all 140 participants, the mean age of women in the intervention group was 28.47 ( $\mathrm{SD} \pm 3.512$ ) years and the mean age in the control group was $28.24(\mathrm{SD} \pm 3.821)$ years. Most of them were 9th graders (60\%), house wives $(94.3 \%)$, and belonged to a nuclear family ( $\leq 4$ people in household) $(87.1 \%)$, had a monthly family income under the average expenditure per capita per month in Aceh (75.7\%), and were multigravida (48.6\%). All of the anemic pregnant women were in their second trimester of pregnancy (median of 20 weeks) when invited to the study (Table 1). The hemoglobin level was measured at a range of $9-10 \mathrm{~g} / \mathrm{dL}$ (mild anemia), and hematocrit level at a range of 29-33\%.

\section{Hemoglobin and Hematocrit Level, Birth Weight, Knowledge of Anemia, Iron-Rich Food Intake, Number of IFA Intake}

Table 2 presents the ANCOVA results of all outcomes. It was found that the primary outcome; post-test hemoglobin

Table I Baseline Comparison on Socio-Demographic and Pregnancy Characteristics of Participants $(n=\mid 40)$

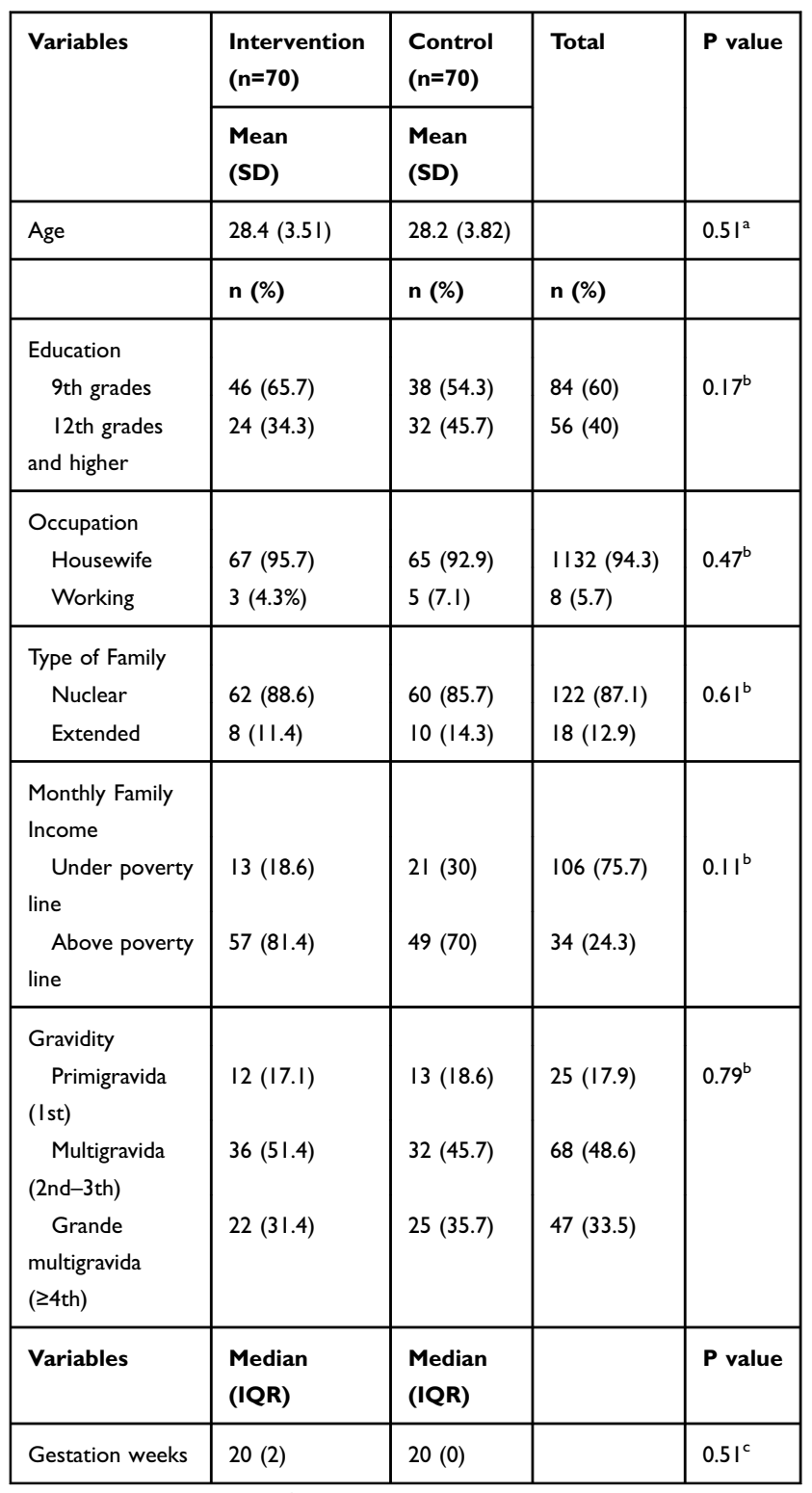

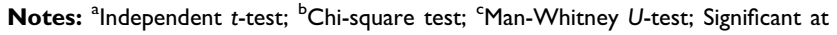
$\mathrm{p}$-value $<0.05$. 
Table 2 ANCOVA Results of the Intervention Program (Post-Test of Hemoglobin and Hematocrit Level, Birth Weight, Knowledge of Anemia, Iron from Food and IFA Intake) for Intervention and Control Group $(n=\mid 40)$

\begin{tabular}{|c|c|c|c|c|c|}
\hline Outcome & $\begin{array}{l}\text { Post-Test Experimental Group } \\
\text { Mean (SD) }\end{array}$ & $\begin{array}{l}\text { Post-Test Control Group } \\
\text { Mean (SD) }\end{array}$ & $\mathbf{F}$ & p-value & $\begin{array}{l}\text { Partial Eta } \\
\text { Squared }\end{array}$ \\
\hline Hemoglobin (g/dL) & $11.7(0.37)$ & $10.5(0.50)$ & 122 & $<0.001^{\mathrm{a}}$ & 0.48 \\
\hline Hematocrit (\%) & $35.2(0.81)$ & $31.2(0.92)$ & 373 & $<0.001^{\mathrm{a}}$ & 0.73 \\
\hline Birth weight (gr) & $3324(354)$ & $2975(279)$ & 7.58 & $0.006^{\mathrm{b}}$ & 0.05 \\
\hline Knowledge score & $16.4(2.06)$ & I3.7 (3.0) & 25.6 & $<0.001^{\mathrm{c}}$ & 0.16 \\
\hline Daily iron intake from food ( $\mathrm{mg} /$ day) & $6.5(7.32)$ & $3.8(4.83)$ & 7.71 & $0.006^{\mathrm{c}}$ & 0.54 \\
\hline FFQ score & $57.9(2.69)$ & $48.2(4.6 I)$ & 562 & $<0.001^{\mathrm{c}}$ & 0.80 \\
\hline Number of IFA intake & $55.5(18.69)$ & $23.2(11.62)$ & 662 & $<0.00 \mathrm{I}^{\mathrm{c}}$ & 0.83 \\
\hline
\end{tabular}

Notes: ANCOVA test; adjustment for covariates: ${ }^{a}$ Pre-test, post-test of iron from food, and IFA intake, age, education, monthly family income; ${ }^{b}$ Post-test of hemoglobin, hematocrit level, iron from food, and IFA intake; 'Pre-test, age, education, monthly family income.

level was significantly different between the groups; F (1, $132)=122$, $\mathrm{p}$-value $<0.001$, adjusted for the covariates of pre-test hemoglobin level, post-test of daily iron intake from food, FFQ score, number of IFA intake, age, education, and monthly family income. With the same covariates, significant differences also occurred in post-test hematocrit levels between the groups; F $(1,132)=373$, p-value $<0.001$. The mean of post-test hemoglobin and hematocrit level was higher in the intervention group compared to the control group.

The ANCOVA results showed that birth weight was significantly different between the groups; $F(1,132)=7.58$, p-value 0.006 , adjusted for the covariates of post-test hemoglobin level, hematocrit level, daily iron intake from food, FFQ score, number of IFA intake.

Furthermore, a significant difference between the two groups was also observed with regard to the knowledge of anemia score $(F(1,134)=25.6$, p-value $<0.001)$, the daily iron intake from food $(\mathrm{F}(1,134)=7.71, \mathrm{p}$-value 0.006$)$, the FFQ score $(\mathrm{F}(1,134)=562$, p-value $<0.001)$, and number of IFA intake $(\mathrm{F}(1,134)=662$, p-value $<0.001)$, with adjustment for the covariates of pre-test, age, education, and monthly family income. The greatest effects of the intervention were found in FFQ score and number of IFA intake, while a medium effect was observed for hemoglobin and hematocrit levels.

\section{Discussion}

The results of the present study show that pregnant women who received individual education through an anemia pictorial handbook and counseling had a significant increase in hemoglobin and hematocrit levels, birth weight, knowledge of anemia, iron-rich food intake, and the number of IFA intake compared to the control group.
In the post-test period, there was a highly significant difference between the means of hemoglobin and hematocrit levels of the intervention group compared to those of the control group (p-value $<0.001$ ), on medium effect of intervention program. All anemic pregnant women in the intervention group recovered from anemia during the third trimester of pregnancy, while only $12.9 \%$ of the pregnant women in the control group recovered. Similar results were reported in a quasi-experimental study done in the Tribhuvan University Teaching Hospital in Kathmandu, Nepal, showing that nutrition education emphasizing iron-rich food consumption was positively associated with improved hemoglobin levels. ${ }^{29}$ A randomized study among pregnant women in Ghana indicated a significant positive relationship between dietary practices and improvement of hemoglobin levels in pregnant women. ${ }^{30}$ Similarly, in a pre-test post-test study done at Kaengkhoi Hospital, Saraburi, Thailand, health education focused on participants' knowledge of iron deficiency anemia and compliance of pregnant women regarding iron supplementation, and mean hematocrit levels of pregnant women were significantly improved after 3 months of the intervention program. ${ }^{31}$

There are a substantial amount of studies that have evidenced that babies born to anemic mothers had lower birth weights compared to those born to non-anemic mothers. $^{32}$ In our study, the mean birth weight of the intervention group was higher compared to that of the control group (p-value $<0.005)$. There were three lowbirth-weight $(<2500$ gram) babies in the control group. Other studies are in agreement with the present study, and demonstrate the importance of normal hemoglobin levels on pregnancy outcomes. ${ }^{33-36}$

Furthermore, this study's results showed highly significant improvement in mean knowledge of anemia, daily 
iron intake from food (mg/day), FFQ score, and number of IFA intake (Table 2) for pregnant women in the intervention group. At pre-test period, there was a lack of knowledge on the seriousness of anemia and the association of nutrition with anemia among anemic pregnant women in both groups. Similar to studies in India, pregnant women were unaware that iron-rich food can improve anemia status, citrus fruit can promote iron absorption, ${ }^{37,38}$ however mother responded correctly that the fetus would be affected by severe anemia. ${ }^{38}$ We educated pregnant women the impact of anemia to mother and child health through a diagram, likewise promoted many of iron-rich foods through pictures that are available in our pictorial handbook (Supplementary figures; English translation of supplementary figures).

We noted the enhancement of iron-rich food intake in diversity, weight of food (portion) and frequency of intake. In fact, there was a large effect of our intervention program on FFQ score. In other hand, the significant improvement of the daily iron intake from food $(\mathrm{mg} / \mathrm{day})$ in the intervention group was not met the recommended daily allowances (RDA) of Indonesia; 39mg/day for third-trimester pregnancy. Several studies that consistent with current study were reported in Bogor, Indonesia; a mean intake of $16 \mathrm{mg}$ / day, ${ }^{7}$ in China; $18.7 \mathrm{mg} /$ day of recommended $30 \mathrm{mg} /$ day ${ }^{39}$ in London; $13 \mathrm{mg}$ /day of recommended $27 \mathrm{mg} /$ day,${ }^{40}$ in Kenya; $29.9 \mathrm{mg} /$ day of recommended $30 \mathrm{mg} /$ day $^{41}$ The common intake from non-heme has more varieties than heme; indeed, it is difficult to fill the need for iron from diet alone. ${ }^{42}$

The mean of IFA intake in the intervention group was 56 tablets $(61.1 \%)$, out of the minimum recommendation of 90 tablets, while the mean intake in the control group was 23 tablets (25.6\%). Many studies in Indonesia, ${ }^{5,43,44}$ and others countries, ${ }^{45,46}$ measured IFA intake for a minimum of 90 tablets or more during their pregnancy, regardless of regularity. The gastrointestinal side effects of the iron supplements were observed as the major deterrent to compliance with iron supplementation in this population, as reported at the end line of study by $41.4 \%$ pregnant women in the intervention group and $57.1 \%$ in the control group. Our midwives had advised women to take IFA with food, ${ }^{47-49}$ or during bedtime to reduce the effect of nausea. ${ }^{49}$ Studies reported that citrusy smells, such as those from a freshly sliced lemon, ${ }^{50}$ Vitamin B6, ${ }^{51,52}$ may help reduce nausea in pregnant women. Procurement of high-quality tablets is also expected to improve compliance because the color, size, coating, and packaging of iron tablets can affect consumption behavior. ${ }^{53}$ While a study of IFA tablet versus capsule resulted in better compliance in the capsule group, the difference was not statistically significant and pregnant women who received either of the formulations reported low compliance. ${ }^{54}$

In Indonesia, the iron-fortified food program is available to flour rather than rice, whereas $97.7 \%$ of the Indonesian population consumes rice every day. ${ }^{55} \mathrm{~A}$ publication by Better Rice Initiative Asia (BRIA) in 2016 stated that rice fortification technology (prototypes of equipment and machineries) is available in Indonesia. ${ }^{56}$ They conducted an intervention (fortified rice) study among teenage girls in boarding school in Kota Medan, Indonesia, that successfully decreased the prevalence of anemia by $41.4 \%$, the prevalence of ferritin by $7.4 \%$, and folic acid deficiency by $3.2 \%$ for girls in the intervention group. ${ }^{56}$

Recently, in August 2019, the national logistics agency of Indonesia launched rice fortified with micronutrients such as vitamin A, vitamin B1, vitamin B3, vitamin B6, vitamin B9, vitamin B12, iron, and zinc for 20.000 IDR per kilogram (1.14 USD) ${ }^{57}$ However, information on the response to this program - the preference to eat, willingness to buy, and the effects on the nutritional status of people in Indonesia - is limited.

The findings of the present study were expected in relation to HBM model constructs; if people have a higher perception of threats or health problems, they take into account possible health warnings that may occur, and thus take action to prevent health problems or health threats and make great changes in their attitudes and behaviors. ${ }^{13}$ The results of the present study agree with Khoramabadi et al, ${ }^{15}$ Baharzadeh et al, ${ }^{58}$ Mohaddesi et al, ${ }^{59}$ and Salama AM, ${ }^{18}$ who reported that education in constructs of HBM has improved knowledge of nutrition during pregnancy, as well as nutritional behavior.

Individual education through a pictorial handbook of anemia in conjunction with counseling in this study had a positive impact on the improvement of hemoglobin and hematocrit levels in anemic pregnant women in their third trimester of pregnancy.

\section{Strengths, Limitations and Recommendations}

The first strength of our study is that we developed our own educational material, which was validated by health professionals and pre-tested on pregnant women. Second, our study described behavioral changes over a longer period of time (average of 15 weeks) than other similar studies. 15,58,60,61 
The third strength of this study is that the outcome variables were not measured solely by a questionnaire-based source or a subjective self-report, but also by the objective measurement of biological markers such as hemoglobin and hematocrit concentrations. The scientific literature in every social science discipline worldwide reports the frequent recall biases and socially-desirable-answer biases linked to questionnaire-based self-reported behavior. Hence, a selfreported questionnaire-based measurement is strengthened by the addition of measurements of biological markers, as performed in this study.

However, there were some limitations in this study. The first limitation is that iron deficiency status was determined by decreased levels of serum ferritin, serum iron, and transferrin saturation with an elevated total ironbinding capacity. ${ }^{62}$ The limitation of the present study is the fact that it did not provide these laboratory tests. The second limitation is that the birth weight outcome was measured by questionnaire-based assessments and subjective self-reports, which are subject to the abovementioned biases. Given the limited numbers of study participants, it would have been feasible and much more reliable to measure pregnancy outcome by reviewing the delivery records at the health facilities where the participants delivered their babies. Record biases and socially desirable answer biases are linked to questionnaire-based self-reported behavior. Hence, validation of self-reported questionnaire-based measurement is needed. The third study limitation is that only pregnant women aged 20 years or older were included in the study. However, while it is known that all pregnant women are most vulnerable to anemia, ${ }^{4}$ anemia in adolescents is well documented in the literature, ${ }^{63,64}$ as well as in individual studies conducted in high income, ${ }^{65}$ middle income, ${ }^{66}$ and low-income areas. ${ }^{67}$ The fourth limitation is that the present study did not discuss the number of antenatal care visits. The fifth limitation is the possibility that our population of study might have visited antenatal care in private clinics and received another brand of iron supplement. The sixth limitation is that this study employs a quasiexperimental design, meaning any causal conclusions are not really allowed. The seventh limitation is the absence of relevant confounding factors such as nutritional status and body mass index (BMI) before pregnancy.

Based on these results, we can make recommendations for future studies on anemia: The first is to run the serum ferritin test to gain a more valid measurement of the iron level in the blood. The second is to review the pregnancy outcome data from the record of the health care facilities where the participants delivered their babies. The third is to include pregnant women below 20 years as they are vulnerable to anemic pregnancy as well. The fourth is to include in the assessment the number and source of antenatal care visits (government, private or both sources). The fifth is to record and evaluate the effect of iron supplement intake according to the source of iron supplement (government, private or both sources) on iron in the blood.

We can also make recommendation for health policy: The first recommendation is to emphasize nutrition education during antenatal care, focusing on behavioral intake of affordable and available local foods, and the intake of the iron supplements on a regular basis. Another is to resolve the nauseating effect of iron-folic acid supplement as this was the majority side effect reported by our population in the study. Our third recommendation is for the Indonesian government to support rice fortification research and studies to collect comprehensive evidence so that the fortified rice can be consumed by a larger proportion of the populace.

\section{Conclusion}

Our findings indicate the effectiveness of providing individual education and counseling to anemic pregnant women in the province of Aceh using a pictorial handbook to improve anemia status, knowledge, encourage an ironrich diet and boost the IFA intake.

\section{Acknowledgments}

This study was supported by the 90th Anniversary of Chulalongkorn University Scholarship under the Ratchadaphisek Somphot Fund, Chulalongkorn University. The authors thank the research teams from the health care offices at Kota Langsa and Kota Lhokseumawe municipalities, province of Aceh, Indonesia. Last, but not least, thanks to Mr. Fadlin Noer who designed the pictorial handbook.

\section{Disclosure}

The authors report no conflicts of interest in this work.

\section{References}

1. World Health Organization. Iron Deficiency Anaemia: Assessment, Prevention and Control, a Guide for Programme Managers. Geneva: World Health Organization; 2011.

2. Sahu K, Idris M, Agarwal M, et al. Effects of anemia during third trimester of pregnancy on gestational size and birth weight of babies in rural Lucknow, India. WJPPS. 2013;2(6):4942-4950.

3. Addis Alene K, Mohamed Dohe A. Prevalence of anemia and associated factors among pregnant women in an urban area of eastern Ethiopia. Anemia. 2014;2014. 
4. World Health Organization. Prevalence of anaemia in pregnant women; 2017. Available from: http://apps.who.int/gho/data/node main.ANEMIA1?lang=en. Accessed January 25, 2019.

5. Ministry of Health Indonesia. National basic health research survey; 2013. Available from: http://www.depkes.go.id/resources/download/gen eral/Hasil\%20Riskesdas\%202013.pdf.8/6. Accessed October 16, 2016.

6. Ministry of Health Indonesia. Indonesia health profile 2017; 2017. Available from: http://www.depkes.go.id/resources/download/pusda tin/profil-kesehatan-indonesia/profil-kesehatan-indonesia-2014.pdf. Accessed January 14, 2019.

7. Madanijah S, Briawan D, Rimbawan R, et al. Nutritional status of pre-pregnant and pregnant women residing in Bogor district, Indonesia: a cross-sectional dietary and nutrient intake study. $\mathrm{Br}$ J Nutr. 2016;116(S1):S57-S66. doi:10.1017/S000711451600057X

8. Rahman MM, Abe SK, Rahman MS, et al. Maternal anemia and risk of adverse birth and health outcomes in low- and middle-income countries: systematic review and meta-analysis, 2. Am J Clin Nutr. 2016;103(2):495-504. doi:10.3945/ajcn.115.107896

9. Mayén A-L, de Mestral C, Zamora G, et al. Interventions promoting healthy eating as a tool for reducing social inequalities in diet in lowand middle-income countries: a systematic review. Int $J$ Equity Health. 2016;15(1):205. doi:10.1186/s12939-016-0489-3

10. Garcia-Retamero R, Cokely ET. Effective communication of risks to young adults: using message framing and visual aids to increase condom use and STD screening. J Exp Psychol. 2011;17(3):270.

11. Luna D, Almerares A, Mayan JC, Gonzalez Bernaldo de Quiros F, Otero C. Health informatics in developing countries: going beyond pilot practices to sustainable implementations: a review of the current challenges. Healthc Inform Res. 2014;20(1):3-10. doi:10.4258/ hir.2014.20.1.3

12. Central Bureau Statistic Indonesia. Telecommunication Statistic in Indonesia 2017. Jakarta: Bureau of Statistics Indonesia; 2018.

13. Orji R, Vassileva J, Mandryk R. Towards an effective health interventions design: an extension of the health belief model. Online J Public Health Inform. 2012;4(3).

14. Jones CL, Jensen JD, Scherr CL, Brown NR, Christy K, Weaver JJ. The health belief model as an explanatory framework in communication research: exploring parallel, serial, and moderated mediation. Health Commun. 2015;30(6):566-576.

15. Khoramabadi M, Dolatian M, Hajian S, et al. Effects of education based on health belief model on dietary behaviors of Iranian pregnant women. Glob J Health Sci. 2016;8(2):230.

16. Araban M, Baharzadeh K, Karimy M. Nutrition modification aimed at enhancing dietary iron and folic acid intake: an application of health belief model in practice. Eur J Public Health. 2017;27(2):287-292.

17. Diddana TZ, Kelkay GN, Dola AN, Sadore AA. Effect of nutrition education based on health belief model on nutritional knowledge and dietary practice of pregnant women in Dessie town, Northeast Ethiopia: a cluster randomized control trial. J Nutr Metab. 2018;2018.

18. Salama AM. Utilizing health belief model to enhance the preventive behavior against iron-deficiency anemia among pregnant women. IOSR-JNHS. 2018;7:59-69.

19. Health office of Aceh. Health profile of Aceh 2017. Banda Aceh: Health office of province Aceh; 2017.

20. Central Bureau of Statistik Province Aceh. Aceh in Numbers 2017. Banda Aceh: Bureau of Statistics Indonesia; 2017.

21. Girard AW, Olude O. Nutrition education and counselling provided during pregnancy: effects on maternal, neonatal and child health outcomes. Paediatr Perinat Epidemiol. 2012;26(s1):191-204. doi:10.1111/ppe.2012.26.issue-s1

22. Ministry of Health Indonesia. Regulation Minister of Health Indonesia Number 97 Year 2014 about health services for pregnant, labor, contraceptive services, and sexual health services; 2014. Available from: http://kesga.kemkes.go.id/images/pedoman/PMK\% 20No.\%2097\%20ttg\%20Pelayanan\%20Kesehatan\%20Kehamilan. pdf. Accessed November 1, 2016.
23. Turner RC, Carlson L. Indexes of item-objective congruence for multidimensional items. Int J Test. 2003;3(2):163-171. doi:10.1207/ S15327574IJT0302_5

24. Fadlun AF. Pathological Midwifery Care. Jakarta: Salemba Medika; 2012.

25. Association of nutritionists Indonesia. Nutrition; Theory and Application. Jakarta: Penerbit Buku Kedokteran EGC; 2016.

26. Schlundt DG, Buchowski MS, Hargreaves MK, Hankin JH, Signorello LB, Blot WJ. Separate estimates of portion size were not essential for energy and nutrient estimation: results from the Southern Community Cohort food-frequency questionnaire pilot study. Public Health Nutr. 2007;10(3):245-251. doi:10.1017/S1368980007258574

27. Głąbska D, Guzek D, Ślązak J, Włodarek D. Assessing the validity and reproducibility of an iron dietary intake questionnaire conducted in a group of young Polish women. Nutrients. 2017;9(3):199. doi:10.3390/nu9030199

28. Association of nutritionists Indonesia. Table of Indonesian Food Composition. Elex Media Komputindo; 2013.

29. Sunuwar DR, Sangroula RK, Shakya NS, Yadav R, Chaudhary NK, Pradhan PM. Effect of nutrition education on hemoglobin level in pregnant women: A quasi-experimental study. PLoS One. 2019;14(3):e0213982.

30. Otoo G, Adam Y. Effect of nutrition education with an emphasis on consumption of iron-rich foods on hemoglobin levels of pregnant women in Ghana. FASEB J. 2016;30(1_supplement):410.412.

31. Sirisopa N, Pongchaidecha M. Evaluation of a pharmaceutical care program with pregnant women with iron deficiency anemia. $J$ Sci Technol Ubon Ratchathani Univ. 2015;17(2):53-62.

32. Figueiredo ACMG, Gomes-Filho IS, Batista JET, et al. Maternal anemia and birth weight: a prospective cohort study. PloS one. 2019;14(3):e0212817.

33. Scholl TO. Maternal iron status: relation to fetal growth, length of gestation, and iron endowment of the neonate. Nutr Rev. 2011;69 (supp1_1):S23-S29.

34. James TR. Haemoglobin Concentrations and Indices of Iron Status in the Three Trimesters of Pregnancy and Their Relationship to Foetal Outcome. 2012. The University of the West Indies Theses Collection. Available from: https://uwispace.sta.uwi.edu/dspace/handle/2139/ 1758. Accessed 1 December 2019.

35. Ribot B, Aranda N, Viteri F, Hernández-Martínez C, Canals J, Arija VJ. Depleted iron stores without anaemia early in pregnancy carries increased risk of lower birthweight even when supplemented daily with moderate iron. Hum Reprod. 2012;27(5):1260-1266.

36. Haider BA, Olofin I, Wang M, Spiegelman D, Ezzati M, Fawzi WW. Anaemia, prenatal iron use, and risk of adverse pregnancy outcomes: systematic review and meta-analysis. BMJ. 2013;346(f3443):f344. doi:10.1136/bmj.f3443

37. Yadav RK, Swamy M, Banjade B. Knowledge and practice of anemia among pregnant women attending antenatal clinic in Dr. Prabhakar Kore hospital, Karnataka-A Cross sectional study. Literacy. 2014;30(34):18.

38. Nelofar M, Mukhtar M, Bashir H. Awareness of anaemia during pregnancy among the pregnant women attending a health facility in District Srinagar. J Med Sci Clin Res. 2018;6. doi:10.18535/jmscr

39. Gao H, Stiller C, Scherbaum V, et al. Dietary intake and food habits of pregnant women residing in urban and rural areas of Deyang City, Sichuan Province, China. Nutrients. 2013;5(8):2933-2954. doi:10.3390/nu5082933

40. Roy A, Evers S, Campbell M. Dietary supplement use and iron, zinc and folate intake in pregnant women in London, Ontario. Chronic Dis Inj Can. 2012;32:76-83.

41. Muthoni MN. 2017. Dietary Diversity, Iron Intake and Iron Status Among Pregnant Women in Embu County, Kenya. Kenya: Foods, Nutrition And Dietetics, In The School Of Applied Human Sciences Of Kenyatta University.

42. Jung Y-M, Choi M-J. Nutrient intake according to weight gain during pregnancy, job status, and household income. Clin Nutr Res. 2017;6 (1):27-37. doi:10.7762/cnr.2017.6.1.27 
43. Titaley CR, Rahayu E, Damayanti R, et al. Association between knowledge and compliance of taking iron/folic acid supplements during pregnancy. Asian J Pharm Clin Res. 2017;10(5):176-182. doi:10.22159/ajpcr.2017.v10s5.23126

44. Triharini M, Sulistyono A, Adriani M, Armini NKA, Nastiti AA. Adherence to iron supplementation amongst pregnant mothers in Surabaya, Indonesia: perceived benefits, barriers and family support. Int J Nur Sci. 2018;5(3):243-248. doi:10.1016/j.ijnss.2018.07.002

45. Lacerte $P$, Pradipasen M, Temcharoen P, Imamee N, Vorapongsathorn T. Determinants of adherence to iron/folate supplementation during pregnancy in two provinces in Cambodia. Asia Pac J Public Health. 2011;23 (3):315-323. doi:10.1177/1010539511403133

46. Ratanasiri T, Koju R. Effect of knowledge and perception on adherence to iron and folate supplementation during pregnancy in Kathmandu, Nepal. J Med Assoc Thai. 2014;97(10):S67-S74.

47. Ogundipe O, Hoyo C, Østbye T, et al. Factors associated with prenatal folic acid and iron supplementation among 21,889 pregnant women in Northern Tanzania: a cross-sectional hospital-based study. BMC Public Health. 2012;12(1):481. doi:10.1186/1471-2458-12-481

48. Ugwu E, Olibe A, Obi S, Ugwu A. Determinants of compliance to iron supplementation among pregnant women in Enugu, Southeastern Nigeria. Niger J Clin Pract. 2014;17(5):608-612. doi:10.4103/1119-3077.141427

49. World Health Organization. Guideline: Iron Supplementation in Postpartum Women; 2016. Available from: https://apps.who.int/iris/ handle/10665/249242. Accessed 1 December 2019.

50. Safajou F, Shahnazi M, Nazemiyeh H. The effect of lemon inhalation aromatherapy on nausea and vomiting of pregnancy: a double-blinded, randomized, controlled clinical trial. Iran Red Crescent Med J. 2014;16(3).

51. Wibowo N, Purwosunu Y, Sekizawa A, et al. Vitamin B6 supplementation in pregnant women with nausea and vomiting. Int J Gynaecol Obstet. 2012;116(3):206-210.

52. Campbell K, Rowe H, Azzam H, Lane CA. The management of nausea and vomiting of pregnancy. $J$ Obstet Gynaecol Can. 2016;38(12):1127-1137. doi:10.1016/j.jogc.2016.08.009

53. Fiedler J, D'Agostino A, Sununtnasuk C. Nutrition Technical Brief: A Rapid Initial Assessment of the Distribution and Consumption of IronFolic Acid Tablets Through Antenatal Care in Bangladesh. Arlington, VA: USAID/Strengthening Partnerships, Results, Project IiNG; 2014.

54. Srivastava R, Kant S, Singh AK, et al. Effect of iron and folic acid tablet versus capsule formulation on treatment compliance and iron status among pregnant women: a randomized controlled trial. J Family Med Prim Care. 2019;8(2):378.

55. Ministry of Health Indonesia. The situation and the nutritional analysis in Indonesia; 2015. Available from: http://www.depkes.go.id/ folder/view/01/structure-publikasi-pusdatin-info-datin.html.

Accessed October 14, 2016.
56. Better Rice Initiative Asia Indonesia. Better rice, better life; 2016. Available from: http://www.better-rice-initiative-asia.org/admin/ upload/resources/23-02-2017-1487828513.pdf. Accessed 28 march, 2019.

57. National logistics agency of Indonesia. Overcoming stunting, government national logistic agency offers fortified rice; healthy rice innovation; 2019. Available from: http://www.bulog.co.id/pers/37/ 7247/13/9/2019/Atasi-Stunting,-Bulog-Tawarkan-Beras-

Fortifikasi-Inovasi-Beras-Sehat-(healthy-Rice)-.html. Accessed 1 December 2019

58. Baharzadeh K, Marashi T, Saki A, Zare Javid A, Araban M. Using of health belief model to promote preventive behaviors against iron deficiency anemia among pregnant women. J Res Health Sci. 2017;7(2):754-762.

59. Mohaddesi H, Rashakani PA, Didarloo A, Khalkhali H. Effect of Intervention Based on Health Belief Model on the Change in Nutritional Behavior of Pregnant Mothers with Iron Deficiency Anemia Referred to Urmia Health Centers. Pharmacophore; 2017.

60. Shivalli S, Srivastava RK, Singh GP. Trials of improved practices (TIPs) to enhance the dietary and iron-folate intake during pregnancy - a quasi experimental study among rural pregnant women of Varanasi, India. PLoS One. 2015;10(9):e0137735. doi:10.1371/ journal.pone.0137735

61. Al-tell MA, El-Guindi FK, Soliman NM, El-Nana HI. Effect of nutritional interventions on anemic pregnant women's health using health promotion model. Med J Cairo Univ. 2010;78(2).

62. Kelly AU, McSorley ST, Patel P, Talwar D. Interpreting iron studies. BMJ. 2017;357:j2513. doi:10.1136/bmj.j2513

63. Cunnington AJ. What's so bad about teenage pregnancy? BMJ Sex Reprod Health. 2001;27(1):36-41.

64. Anisa M Prevalence of anemia in adolescents: a challenge to the global health 2018; https://www.actascientific.com/ASNH/pdf/ ASNH-02-0063.pdf. Accessed March 28, 2019.

65. Briggs MM, Hopman WM, Jamieson MA. Comparing pregnancy in adolescents and adults: obstetric outcomes and prevalence of anemia. J Obstet Gynaecol Can. 2007;29(7):546-555. doi:10.1016/S17012163(16)32506-3

66. Pinho-Pompeu M, Surita FG, Pastore DA, Paulino DSM, Pinto e Silva JL. Anemia in pregnant adolescents: impact of treatment on perinatal outcomes. J Matern Fetal Neonatal Med. 2017;30 (10):1158-1162. doi:10.1080/14767058.2016.1205032

67. Chalise B, Aryal KK, Mehta RK, et al. Prevalence and correlates of anemia among adolescents in Nepal: findings from a nationally representative cross-sectional survey. PLoS One. 2018;13(12):e0208878. doi:10.1371/journal.pone.0208878
Journal of Multidisciplinary Healthcare

\section{Publish your work in this journal}

The Journal of Multidisciplinary Healthcare is an international, peerreviewed open-access journal that aims to represent and publish research in healthcare areas delivered by practitioners of different disciplines. This includes studies and reviews conducted by multidisciplinary teams as well as research which evaluates the results or conduct of such teams or healthcare processes in general. The journal covers a very wide range of areas and welcomes submissions from practitioners at all levels, from all over the world. The manuscript management system is completely online and includes a very quick and fair peer-review system. Visit http://www.dovepress.com/testimonials. php to read real quotes from published authors. 